\title{
A Comparative Analysis of the Relation between Political Trust and Forms of Political Participation in Europe
}

\section{European Societies, 14, accepted}

[Imp.F. 0.682]

\begin{abstract}
In the literature, two competing claims can be found on the relationship between political trust and political participation. While some authors argue that trust is a prerequisite for any form of participation to occur, others claim that distrust can be a motivating factor for participation in non-institutionalised forms of participation. The social movement literature suggests that political trust will only have these behavioural consequences if it is associated with sufficiently high levels of political efficacy. In this article, we rely on the results of the 2006 European Social Survey for an in-depth analysis of the relationship between political trust and participation in 25 countries. The multi-level regression shows that while political trust is positively associated with institutionalised participation, it is negatively associated with noninstitutionalised participation. Moreover, the effect of political trust on institutionalised participation is dependent on self-confidence about one's capability to understand politics.
\end{abstract}

Keywords: political participation, political trust, European Social Survey 


\section{Introduction}

Does it make sense to participate in political life, if one does not trust the political system or political decision-makers? This is one of the perennial questions in political sociology, from the moment on a systematic decline in political trust was first documented in the late 1960s (Levi and Stoker 2000). As Citrin (1974, p. 980) already argued: 'The standard hypothesis, of course, is that political disaffection (cynicism, alienation) is associated with a rejection of conventional or "conformist" models of political participation (...) the politically cynical should be more likely than those who trust the government either to withdraw from political activity altogether or to engage in noncustomer, sometimes illegal, activities such as participating in sit-ins or riots, or organizing for revolution'. In this quote, the words 'either/or' - italicised in the original text - are of crucial importance. If low levels of political trust would be associated with low participation levels, one could argue that this phenomenon poses a threat to the stability of the political system, as we can assume that participation is a key characteristic of stable democratic political systems (Barber 1984). If, on the other hand, institutionalised participation would merely be replaced by non-institutionalised forms of participation, this implies that political systems will have to adapt to new forms of interaction with the population (Inglehart and Welzel 2005; Rosanvallon 2008). It is therefore of crucial importance to determine whether low levels of political trust are associated with a complete withdrawal from political life, or whether this 'only' leads to a change in the political participation repertoires being used by distrusting citizens. In this article, we want to investigate whether political trust is indeed a necessary resource for political participation.

The relations under investigation are inherently complex. It can be assumed that political trust has a positive impact on some forms of participation, but not on others. Furthermore, we 
know that political mobilisation processes are the result of a complicated interplay between various elements: issue salience, mobilisation efforts, socio-economic status, civic skills, interest, motivation, political opportunity, political trust and political competence and awareness (Verba et al. 1995). From this perspective, political trust can still be considered as an essential prerequisite for political participation to occur, but it should not be considered as a sufficient prerequisite: political trust can only be expected to have a positive effect on participation levels if it is combined with other civic resources. While there is a general consensus that both political trust and efficacy are important resources for participation, there is disagreement on the nature of this relationship: are the effects of political trust and efficacy on political participation simply additive or are both attitudes required? Some authors state that political trust and efficacy are two essential prerequisites and only their joint presence will trigger political action (Gamson 1968; Fraser 1970). Empirical studies testing this theoretical expectation yielded mixed results and the interplay between both attitudes has not yet been tested in a large cross-national study.

In this article, we propose to build on prior research not just by using new comparative data and carefully constructed measurements, but also by paying attention to the occurrence of interaction effects between political trust and elements of political efficacy. In this article we first review the theoretical and empirical literature on the relationship between political trust and political participation, before we move on with our own analysis on the relationship between political trust, institutionalised participation, non-institutionalised participation and voting. 


\section{Data and methods}

In order to assess the relation between political trust and political participation, we need access to a dataset that includes a comprehensive and reliable measurement of both variables. The third wave of the European Social Survey (2006) provides extensive and up-to-date information on trust in institutions, participation and various political attitudes (Jowell et al. 2007). The advantage of using this cross-country dataset is that we can be confident that any results we might find are not dependent on specific characteristics of one country or one political system. As we know there are large country level differences between participation levels, it is clear that findings from a single country cannot be generalized toward Western societies. As open democratic governance structures tend to be associated with high levels of political participation, it is important to control for basic elements of the political system in order to study political participation levels, as was already noted by Jennings, Van Deth et al. (1990). Comparative data, therefore allow us more certainty that any results we might find are not due to specific country level characteristics. Data was collected in 2006-2007 by means of face-to-face interviews among representative samples of the population of 25 European countries. Response rates varied by country with a median of 63.4 per cent.

\section{Dependent variable: Political participation}

The European Social Survey (2006) provides an extensive list of political activities in which respondents can participate. Institutionalised forms of participation include party membership, working in a political party or action group at least once during the last year and contacting government officials at least once during the last year. Further, respondents were also asked 
whether they had voted during the last national election, and given the very specific characteristics and distribution of this participation act, we decided to analyse it separately. By doing so, we are in line with most of the political participation literature. Voting remains by far the most widespread form of political participation. Contrary to other forms of participation, voting is legally limited in use to one vote for every person and in some countries, voting is compulsory (e.g. Belgium). Non-institutionalised forms of participation, on the other hand, include having signed a petition, boycotted products, and having taken part in a demonstration.

Our distinction between institutionalised and non-instititutionalised forms of participation closely follows the framework already set out by Barnes and Kaase (1979). Institutionalised forms of participation are defined and organised by members of the political elite (most notably political parties), while non-institutionalised forms of participation in practice are being used predominantly by non-elite actors, in order to challenge the political elite or to gain access to the political agenda (Inglehart 1997). This distinction is in line with the literature in this regard (e.g. Inglehart and Catterberg 2002; Marien et al. 2010; Dalton 2008) and it is also empirically valid as a confirmatory factor analysis demonstrates these are distinct dimensions.

To summarise, we have three dependent variables: institutionalised participation, noninstitutionalised activities and voting. All three dependent variables are categorical with a value $0=$ not done and a value $1=$ done.

\section{Independent variables}

The main independent variable is political trust. We operationalise diffuse political trust by measuring trust in the most important institutions of a political system (Muller and Jukam 
1983). The question on political trust was phrased: "please tell me on a score of 0 to 10 how much you personally trust each of the institutions I read out. 0 means you do not trust an institution at all, and 10 means you have complete trust'. The institutions include: the national parliament, politicians, political parties, the legal system and the police. A principal component analysis indicated that the items load strongly on a single dimension, explaining over half of the total variance with an Eigenvalue of 3.55 and Cronbach's $\alpha$ of 0.89 (Table 1).

\section{$===$ TABLE 1 ===}

As already argued, political efficacy too can be considered as an important determinant of political participation. Niemi et al. $(1991,1407)$ note that political efficacy has two components, as it refers to the self-perceived ability to understand politics and to participate in an effective manner. Unfortunately, the ESS questionnaire did not include a full measurement of internal political efficacy, but only includes two questions on the cognitive awareness with regard to politics. Based on the statistical material presented by Niemi et al. (1991) it can be assumed that this cognitive awareness will be closely associated with the efficacy with regard to participation, but given the fact that the ESS dataset does not include any information on this matter, for the time being we refer to these two variables as a form of political awareness. The following two items were used: 'How often does politics seem so complicated that you can't really understand what is going on?' and 'How difficult or easy do you find it to make your mind up about political issues?' Both questions tap the feeling that the individual is powerless to understand politics. These variables are correlated (Pearson's correlation: 0.466) and correspond to one underlying factor. 
In our analysis, we also include various control variables. Previous research has indicated that education, gender, age, ethnicity and religion are, to varying extents, related to levels or types of political participation (Verba et al. 1995; Marien et al. 2010; Desposato and Norrander 2008; van Deth and Elff 2004). We included level of education, age, gender, citizenship status and church practice as background variables. Age, level of education and church practice are coded as continuous variables, whereas gender and citizenship status are coded as dichotomy variables (with respectively women $=0$ and $m e n=1$; not a citizen of the country $=0$ and citizen of the country=1; see Appendix for question wording).

Further, we will control for social capital that is often assumed to influence political participation (Hooghe 2003). Based on the literature, we think it is safe to include two elements commonly included in the social capital literature as control variables: generalised trust and networks (Newton 2007). We can assume that trusting people are more likely to engage in collective action. In the ESS, generalised trust was included with three standard questions that strongly correlate and correspond to one factor (with 69.5 per cent explained variance and an Eigenvalue of 2.09). Further, people can be mobilised through networks. Especially, trade unions often mobilise citizens for political action. Therefore, respondents were asked whether they were member of a trade union or a similar organisation. Informal networks were measured by asking respondents: 'How often do you socially meet with friends, relatives or colleagues?' Finally, political participation levels tend to be lower in less established democracies (Kostadinova and Power 2007). Some of the more recent democracies in Central and Eastern Europe still struggle to establish a well-functioning democratic political system. In order to take this effect into account, a composite index of good governance was included in the analyses. This index, developed by the World Bank, is based on expert and citizen surveys and is meant to tap the effective functioning of 
government institutions within a country. The index summarises information on a country with several measures including voice and accountability, upholding the rule of law, fighting corruption, government effectiveness, regulatory quality and offering political stability (Kaufmann et al. 2008).

Given that we are interested in three dependent variables (institutionalised participation, noninstitutionalised participation and voting), we performed three regression analyses. Because all dependent variables are coded as dichotomous variables, we used logistic regressions techniques. Moreover, it is a reasonable expectation that the scores of respondents sampled in the same country will tend to resemble one another, and this nested structure of the data can bias the standard errors which results in spurious significant results. Multilevel analysis allows taking this intra class-correlation and the variance between countries into account (Hox 2002).

\section{Results}

First we explain the occurrence of institutionalised participation (Table 2). The null-model demonstrates that 5 per cent of the variation can be situated at the country level. In Model I, all independent variables are included. In line with hypothesis 1 , we can observe that political trust is positively related to participation in institutionalised participation. The results show that men, highly educated and older citizens participate more often in this form of political action. Political awareness, too, proves to have a significant and very strong effect on institutionalised participation. Further, union membership and integration in informal networks boost institutionalised participation. As expected, participation is higher in countries that have higher values on the good governance index. In this model, approximately 2 per cent of the variance between the countries is explained. Following hypothesis 3, in Model II we 
allow for an interaction effect between political awareness and political trust. This interaction effect proves to be significant suggesting that a combination of political trust and confidence in the ability to understand politics is highly conducive for institutionalised political participation.

\section{$===$ TABLE $2==$}

Second, we explain the occurrence of non-institutionalised participation and here we proceed in a similar manner (Table 3). The null-model shows that 22 per cent of the variation in the dataset can be situated at the country level. In Model III, all independent variables are included. In line with hypothesis 2 , we can observe a negative relation between political trust and non-institutionalised participation. Further, contrary to institutionalised participation, women and younger people participate more often in non-institutionalised than men and older people. Education however remains an important source of inequality in participation. Also for non-institutionalised participation, political awareness plays an important role: the probability that a woman with the lowest level of political awareness will participate is 0.49 , while this is 0.77 for a woman with the highest level of political awareness (holding all other variables constant at their mean). Also social capital proves to be important given that generalised trust, union membership and informal networks all positively contribute to noninstitutionalised participation.

Similar to institutionalised participation, non-institutionalised participation is substantially higher in countries with higher values on the good governance index. The interaction between political trust and political awareness, entered in Model IV does not reach statistical significance. This finding contradicts the earlier studies on this interaction effect (Guterbock and London 1983; Paige 1971; Citrin 1977; Muller 1977). In these 25 societies, a combination 
of political trust and political awareness does not increase the likelihood to engage in noninstitutionalised activity.

$===$ TABLE 3 ===

In the third analysis, we examine citizens' turnout during elections. Therefore, we conduct our analysis on the electorate and eliminated respondents who were not eligible to vote due to their age or citizenship status (Table 4). Again, we start with a null-model, demonstrating that 12.4 per cent of the variation in the dataset can be situated at the country level. Model $\mathrm{V}$ shows that trusting citizens turn out more often. Furthermore, highly educated respondents and older citizens are more likely to vote. Church practice and social capital increase the likelihood to vote. Also for voting, political awareness proves to be important. We can observe, however, that in this case the good governance indicator does not help us to explain the observed differences between countries. Similar to other forms of institutionalised participation, there is a positive interaction effect between political trust and political awareness (Model VI), suggesting that both attitudes motivate voting and that a combination of political trust and awareness boosts voter participation even more strongly.

$===$ TABLE 4 ===

The results reported in the previous tables were obtained using the full ESS sample. We can thus be confident that the findings are not dependent on the characteristics of specific country settings. In order to test for the robustness of the results, we also conducted the analysis country by country. In a large majority of cases, the same patterns were found, although conventional standards of significance were not always reached, due to smaller sample sizes. The relations did prove to be most meaningful in the more established democracies, while they were more volatile in some of the more recent democracies in Central and Eastern 
Europe. This might suggest that the pattern we describe in the analysis might be mostly applicable to established democracies, but this is something that should be investigated more in depth in future research.

\section{Discussion}

In the literature, competing claims have been put forward with regard to the relation between political trust and various forms of political participation. While some authors claim that political trust is a prerequisite for any form of political participation to occur, others assume that a lack of trust can lead to a more intensive form of citizens' participation. In this article, we report on a comprehensive analysis of this relation, using the results of the 2006 European Social Survey. The data that are available in this survey allow us to formulate an answer to the question Citrin already posed 37 years ago: will low levels of political trust be associated with less participation, or rather with different patterns of participation? The evidence presented in this article suggests that the latter option is the case: while citizens with high levels of political trust are more likely to engage in institutionalised forms of political participation (thus confirming hypothesis 1), political trust is negatively associated with participation in non-institutionalised forms (confirming hypothesis 2). For voting, a positive relation with political trust could be observed. Our first two hypotheses are thus clearly confirmed: political trust seems to boost institutionalised participation and voting in particular but reduces non-institutionalised participation. It has to be acknowledged, however, that the results of the analysis were strongest for the act of voting and this lends some support to the hypothesis that the decline of political trust could be regarded as an important causal factor for the observed decline in voter turnout in a number of liberal democracies. Whether the loss in voter turnout can be compensated by a simultaneous rise in non-institutionalised 
participation as a method for citizens to gain political influence is a question that falls beyond the scope of the current article.

Self-confidence about one's capability to understand politics also proved to have a strong effect on all forms of political participation. In 1968, William Gamson stated that a combination of distrust and high efficacy would serve as an ideal breeding ground for political action. Partly, the current analysis confirms the notion that both variables are important and interact with one another. The interaction effects, however, are different than Gamson would have assumed. For institutionalised participation and voting the analysis revealed that a combination of trust and awareness leads to high participation figures. For this kind of participation repertoire, we can indeed conclude that an interaction occurs between both resources for participation, thus confirming hypothesis 3 . This implies that participation levels will be highest among those that trust the system and also have confidence in their own way capability to understand the political system. But while distrust and awareness, on their own, are related to non-institutionalised participation, for this kind of participation we did not observe any significant interaction effect - contrary to Gamson's predictions and hypothesis 3. Distrusting citizens are more likely to engage in non-institutionalised politics but their participation levels do not receive a stronger boost from their capability to understand politics than is the case among trusting citizens. However, the findings of this study are limited to one element of internal efficacy, the confidence in one's ability to understand politics. Data limitations did not allow us to investigate the effect of a second element of internal efficacy, the belief in one's own capability to participate.

The result of the analysis is that institutionalised participation and voting are rather straightforward to predict. Those who trust the system and feel capable to understand it, opt 
for this kind of participation repertoire, and they do so even more intensively if both feelings are present simultaneously. For non-institutionalised participation, on the other hand, the image remains less clear. Those who distrust the system indeed more often join these kinds of action, but this effect is not moderated by the feeling of political awareness. This might suggest that political distrust might be a strong mobilizing force across society, and that it is not dependent on the capability of citizens to actually understand politics. While Gamson in the 1960's quite strongly argued that protest should be seen as an instrumental way of changing society and the political system, the current analysis suggest that noninstitutionalised participation is less strongly dependent on one's ability to understand political life. As such, it seems less strongly correlated to the explicit goal of bringing about changes in the political system than more institutionalized forms of political participation. To ascertain whether this is indeed the cause for the changes we detected in this analysis, however, needs to be further investigated. The fact that these are only European data limits the variance with regard to country level variables, so it would be extremely interesting to investigate this relation using a most different case design, also including countries with closed political systems.

The analysis strongly supports the idea that low levels of political trust should not be equated with low across the board levels of citizen participation and maybe even on the contrary: distrusting citizens are more likely to participate in a whole range of political activities. The current analysis therefore seems to strengthen the claim put forward by Norris, Rosanvallon and other authors: low levels of political trust do not imply an alienation from the political system as such, but rather indicate a structural trend towards different forms of interaction between citizens and the political system. This does not imply, self-evidently, that this trend towards new forms of citizen-state interaction could not entail new problems. To start with, 
we do not know how effective these forms of non-institutionalised politics actually are. While it might be worthwhile that citizens participate in demonstrations and boycott products for political reasons, we do not know yet how effective these forms of participation are. There is some anecdotal evidence suggesting that demonstrations might have changed the nature of political decision-making (Deneckere, 1993; Tilly, 2008), but currently there is no research available demonstrating that on a routine basis too this might be considered as an effective form of input into the political decision-making process. The transition towards new interaction patterns between citizens and the political system inevitably creates a number of uncertainties: we know what we lose (i.e., the quasi general character of voting) but we do not know yet whether the emerging alternatives are really effective in ensuring that the view of citizens get represented in the political decision making process. 
Table 1. Principal Component Analysis for Political Trust Items

\begin{tabular}{lr}
\hline Trust in... & Lo \\
\hline Country's parliament & 0.867 \\
The legal system & 0.825 \\
The police & 0.757 \\
Politicians & 0.887 \\
Political parties & 0.868 \\
Eigenvalue & 3.55 \\
Percentage explained variance & 70.91
\end{tabular}

Results of a principal component analysis on full ESS 2006 sample. (43,733 individuals in 25 countries) 
Coefficient S.E. Coefficient S.E.

\begin{tabular}{lllll}
\hline Political trust & $0.043^{* * *}$ & 0.008 & $0.032 * * *$ & 0.008 \\
Political awareness & $0.355^{* * *}$ & 0.016 & $0.353^{* * *}$ & 0.016 \\
Education & $0.261^{* * *}$ & 0.015 & $0.262^{* * *}$ & 0.015 \\
Gender (Male= 1) & $0.220^{* * *}$ & 0.027 & $0.217 * * *$ & 0.027 \\
Age & $0.010^{* * *}$ & 0.001 & $0.010^{* * *}$ & 0.001 \\
Citizen status & $0.515^{* * *}$ & 0.084 & $0.511^{* * *}$ & 0.084 \\
Church practice & $0.116^{* * *}$ & 0.010 & $0.117 * * *$ & 0.010 \\
Generalised trust & $-0.024 * *$ & 0.008 & $-0.023 *$ & 0.008 \\
Union membership & $0.272^{* * *}$ & 0.033 & $0.272^{* * *}$ & 0.033 \\
Informal networks & $0.194 * * *$ & 0.017 & $0.195 * * *$ & 0.017 \\
Good governance (country level) & $0.298^{* *}$ & 0.093 & $0.301 * *$ & 0.093 \\
Political trust * political & & & $0.028 * * *$ & 0.007 \\
awareness & & & & \\
Intercept & $-2.756 * * *$ & 0.109 & $-2.754 * * *$ & 0.109 \\
Intra-Class Correlation (\%) & $2.80 \%$ & & $2.80 \%$ & \\
Between country error variance & 0.094 & 0.028 & 0.094 & 0.028 \\
\hline
\end{tabular}

Source: ESS (2006). N=40,222 individuals in 25 countries. Notes: Results of logistic multilevel analyses. Method of estimation: PQL. The variables were centred. Variance at country level $=5.48 \%$ in null-model. Sign.: $* \mathrm{p}<0.05 ; * * \mathrm{p}<0.01 ; * * * \mathrm{p}<0.001$. Only 'good governance' added as country level variable, all other variables individual level. 
Table 3. Multilevel Regression Explaining Non-institutionalised Participation

MODEL III

MODEL IV

\begin{tabular}{llllr}
\hline & Coefficients & S.E. & Coefficients & S.E. \\
Political trust & $-0.047^{* * *}$ & 0.007 & $-0.045^{* * *}$ & 0.008 \\
Political awareness & $0.305^{* * *}$ & 0.015 & $0.306^{* * *}$ & 0.015 \\
Education & $0.367^{* * *}$ & 0.014 & $0.367 * * *$ & 0.014 \\
Gender (Male=1) & $-0.223^{* * *}$ & 0.025 & $-0.222^{* * *}$ & 0.025 \\
Age & $-0.008^{* * *}$ & 0.001 & $-0.008^{* * *}$ & 0.001 \\
Citizen status & $0.542^{* * *}$ & 0.070 & $0.544 * * *$ & 0.070 \\
Church practice & $0.019^{*}$ & 0.010 & 0.019 & 0.010 \\
Generalised trust & $0.029 * * *$ & 0.008 & $0.029 * * *$ & 0.008 \\
Union membership & $0.370^{* * *}$ & 0.031 & $0.370^{* * *}$ & 0.031 \\
Informal networks & $0.116^{* * *}$ & 0.016 & $0.116^{* * *}$ & 0.016 \\
Good governance (country level) & $1.114 * * *$ & 0.181 & $1.115^{* * *}$ & 0.181 \\
Political trust * political & & & -0.011 & 0.006 \\
awareness & & & $-2.361 * * *$ & 0.254 \\
Intercept & & & $10.24 \%$ & \\
Intra-Class Correlation (\%) & $10.19 \%$ & & \\
Between country error variance & 0.370 & 0.106 & 0.372 & 0.107 \\
\hline
\end{tabular}

Source: ESS (2006). N= 40,086 in 25 countries. Notes: Results of logistic multilevel analyses (PQL estimation). The variables were centred. Variance at country level $=22.08 \%$ in null-model. Sign.: $* \mathrm{p}<0.05 ; * * \mathrm{p}<0.01 ; * * *$ $\mathrm{p}<0.001$. Only 'good governance' added as country level variable, all other variables individual level. 
Table 4. Logistic Multilevel Regression Explaining Voting MODEL V

MODEL VI

\begin{tabular}{|c|c|c|c|c|}
\hline & Coefficients & S.E. & Coefficients & S.E. \\
\hline Political trust & $0.156 * * *$ & 0.008 & $0.160 * * *$ & 0.009 \\
\hline Political awareness & $0.290 * * *$ & 0.017 & $0.328 * * *$ & 0.018 \\
\hline Education & $0.297 * * *$ & 0.017 & $0.296 * * *$ & 0.017 \\
\hline Gender $($ Male $=1)$ & -0.045 & 0.030 & -0.050 & 0.030 \\
\hline Age & $0.030 * * *$ & 0.001 & $0.029 * * *$ & 0.001 \\
\hline Church practice & $0.168 * * *$ & 0.012 & $0.169 * * *$ & 0.012 \\
\hline Generalised trust & $0.048 * * *$ & 0.008 & $0.049 * * *$ & 0.008 \\
\hline Union membership & $0.461 * * *$ & 0.044 & $0.463 * * *$ & 0.044 \\
\hline Informal networks & $0.070 * * *$ & 0.017 & $0.071 * * *$ & 0.017 \\
\hline Good governance (country & 0.043 & & & \\
\hline level) & & 0.186 & 0.045 & 0.185 \\
\hline $\begin{array}{l}\text { Political trust } * \text { political } \\
\text { awareness }\end{array}$ & & & $0.046 * * *$ & 0.007 \\
\hline Intercept & $0.795 * * *$ & 0.132 & $0.798 * * *$ & 0.131 \\
\hline Intra-Class Correlation (\%) & $10.76 \%$ & & $10.63 \%$ & \\
\hline Between country error variance & 0.393 & 0.113 & 0.388 & 0.112 \\
\hline
\end{tabular}

Source: ESS (2006). $\mathrm{N}=36,518$ individuals in 25 countries. Notes: Results of logistic multilevel analyses (PQL estimation). The variables were centred. Variance at country level $=12.36 \%$ in null-model. Sign.: $* \mathrm{p}<0.05$; ** $\mathrm{p}<0.01 ; * * * \mathrm{p}<0.001$. Only 'good governance' added as country level variable, all other variables individual level. 